Supporting information

\title{
In Situ Analysis of the Li-O 2 Battery with Thermally Reduced Graphene Oxide \\ Cathode: Influence of Water Addition
}

Mie Møller Storm ${ }^{1}$, Mathias Kjærgård Christensen ${ }^{1}$, Reza Younesi ${ }^{2}$ and Poul Norby ${ }^{1}$

${ }^{1}$ Technical University of Denmark, DTU Energy, Frederiksborgvej 399, 4000 Roskilde, Denmark

${ }^{2}$ Department of Chemistry - Ångström Laboratory, Uppsala University, Box 538, SE-751 21 Uppsala,

Sweden

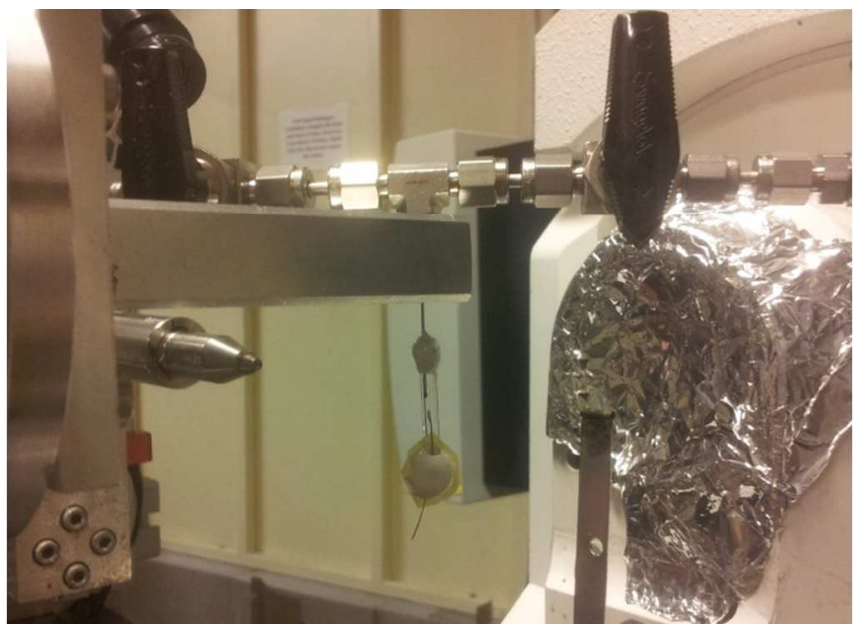

Figure S1: A picture of the capillary battery measured at the Maxlab II, beamline 711. 

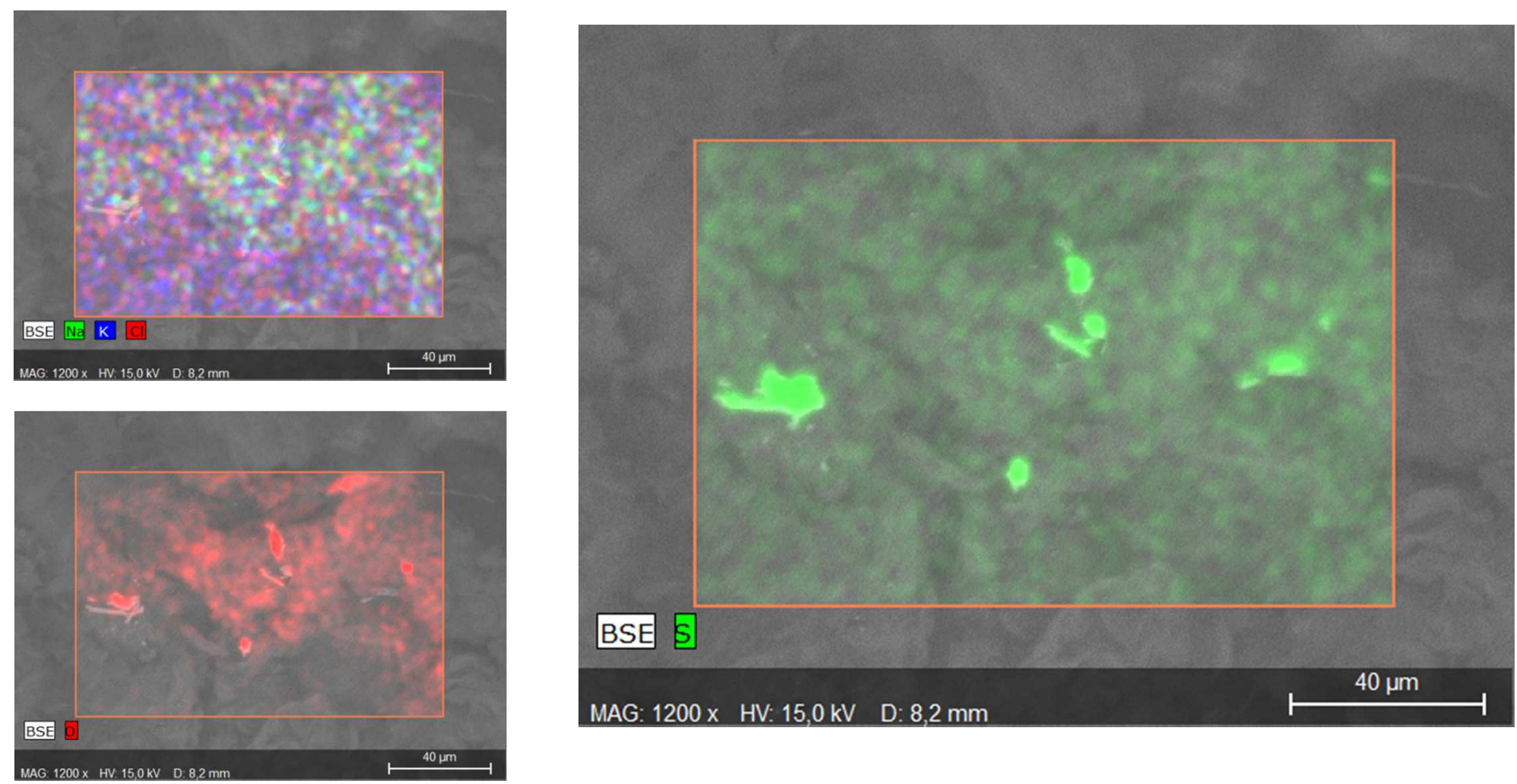

Figure S2: EDX pictures of TrGO of a point in the TrGO sample containing S-rich particles.

\section{EDX}

3 different EDX measurements (300 S, $15 \mathrm{KeV}$, TM3000) revealed the presence of O (67.4-73.5\%), S (14.9-11.9\%), $\mathrm{K}(9.9-7.5 \%), \mathrm{Cl}(6.0-4.0 \%)$ and $\mathrm{Na}(3.9-2.8 \%)$ (C could not be measured by EDX). XPS showed the presence of $\mathrm{C}$ and $\mathrm{O}$, as expected, and $\mathrm{S}$ traces. The sulfur particles observed with SEM-EDX in some areas of the sample are probably created from traces of sulfuric acid in the GO forming particles upon the thermal reduction. 


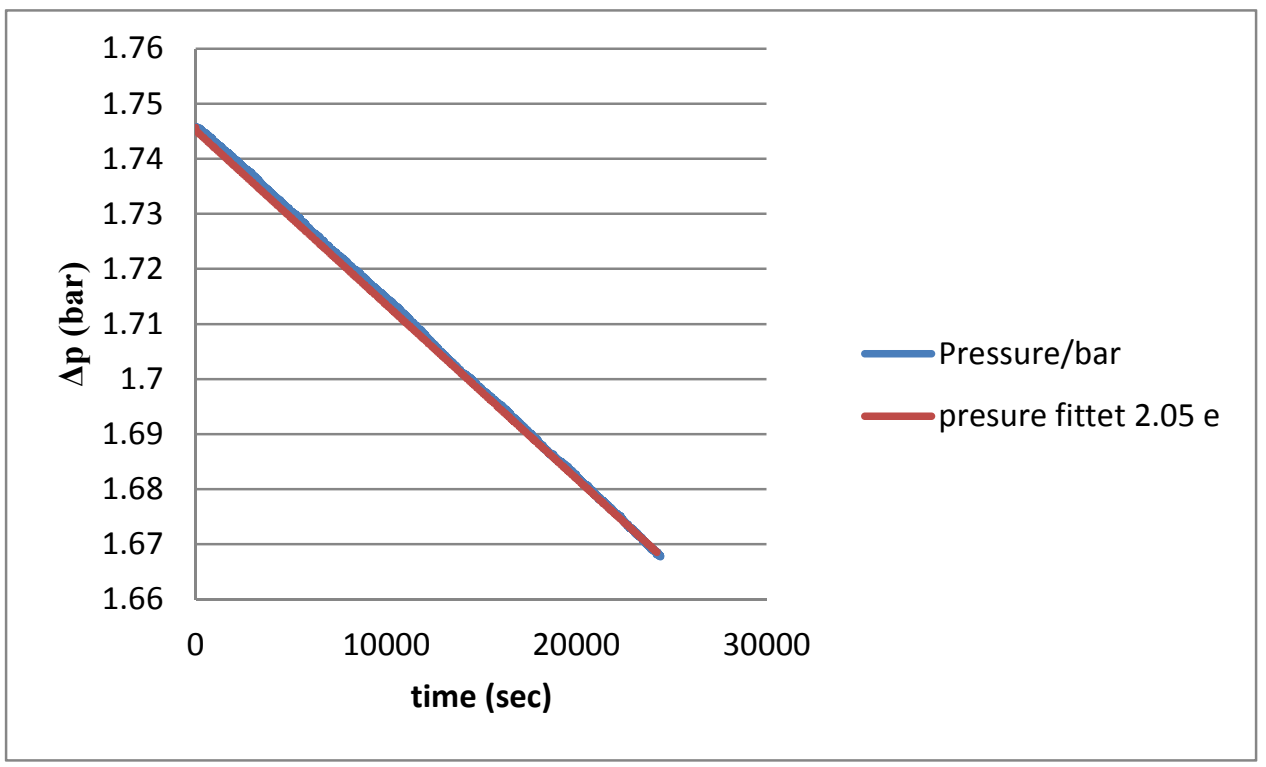

Figure S3: A DEMS discharge pressure measurement of a dry battery with the fitted pressure corresponding to an electron count of $2.05 \mathrm{e}^{-} / \mathrm{O}_{2}$.

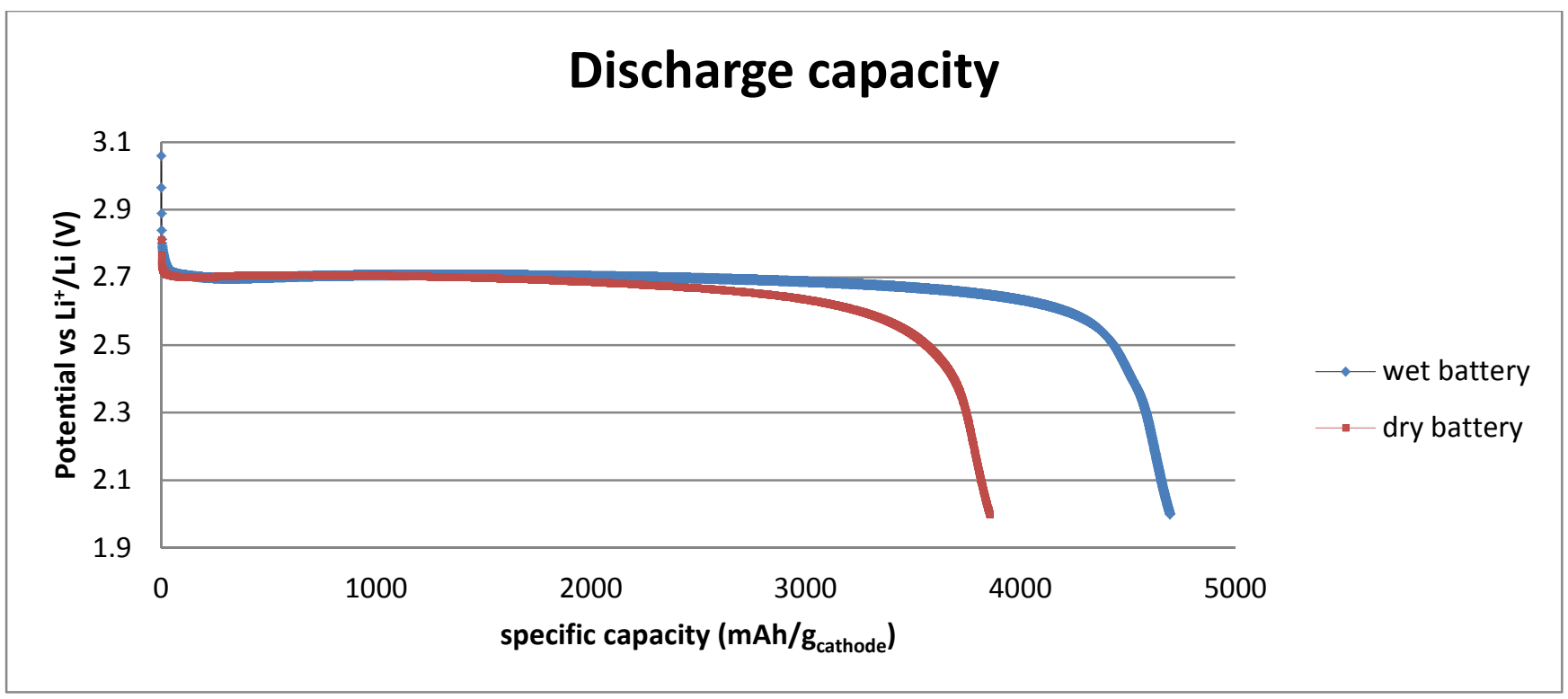

Figure S4: Discharge capacity of a wet and a dry battery calculated from the DEMS data. 


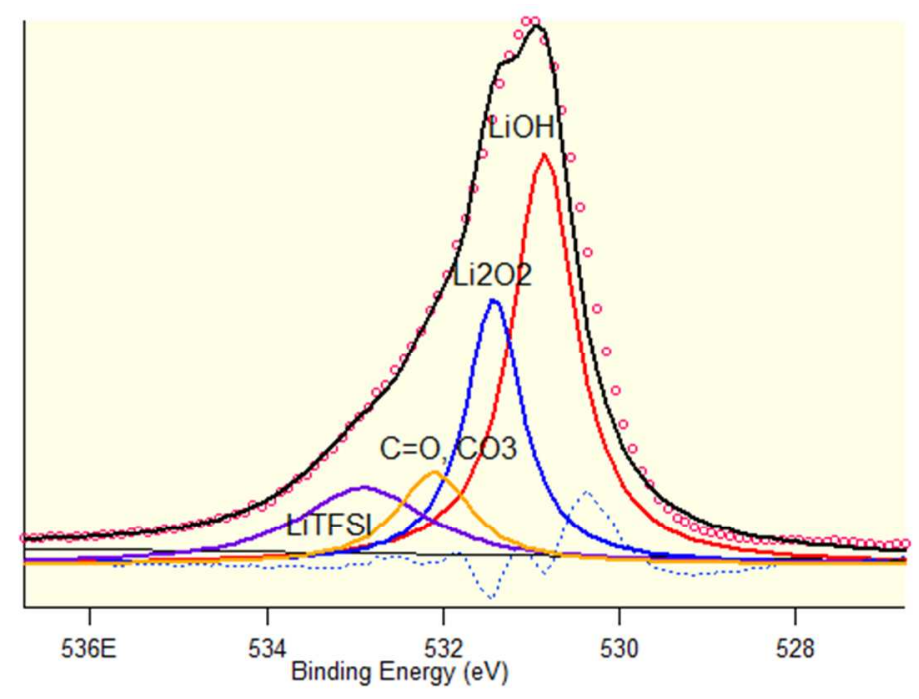

Figure S5: Deconvoluted O 1s XPS spectrum of the dry cathode showing formation of LiOH and $\mathrm{Li}_{2} \mathrm{O}_{2}$ upon discharge.
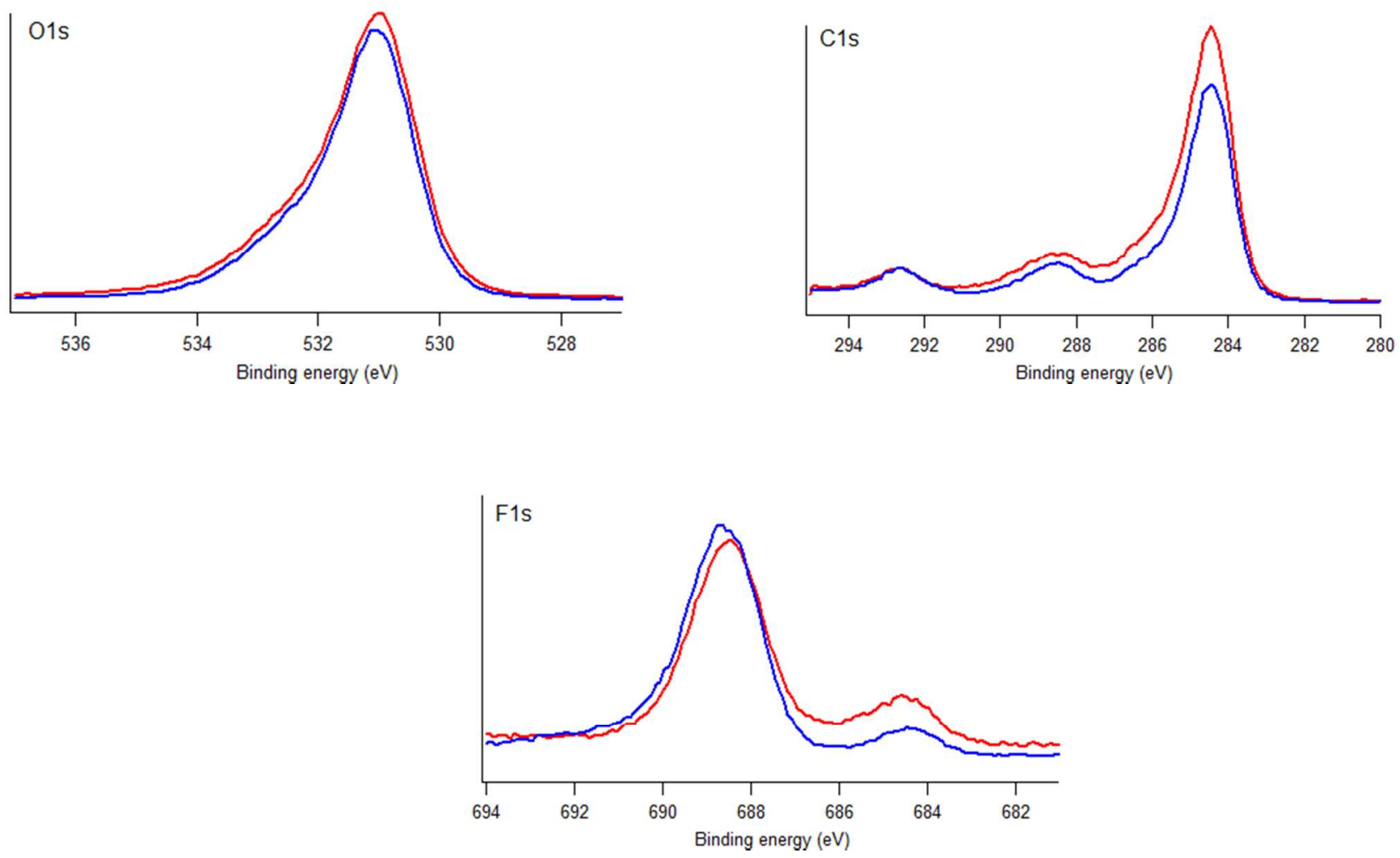

Figure S6: O 1s, C 1s and F 1s spectra of the discharged wet and dry cathode (wet = blue, dry = red) 

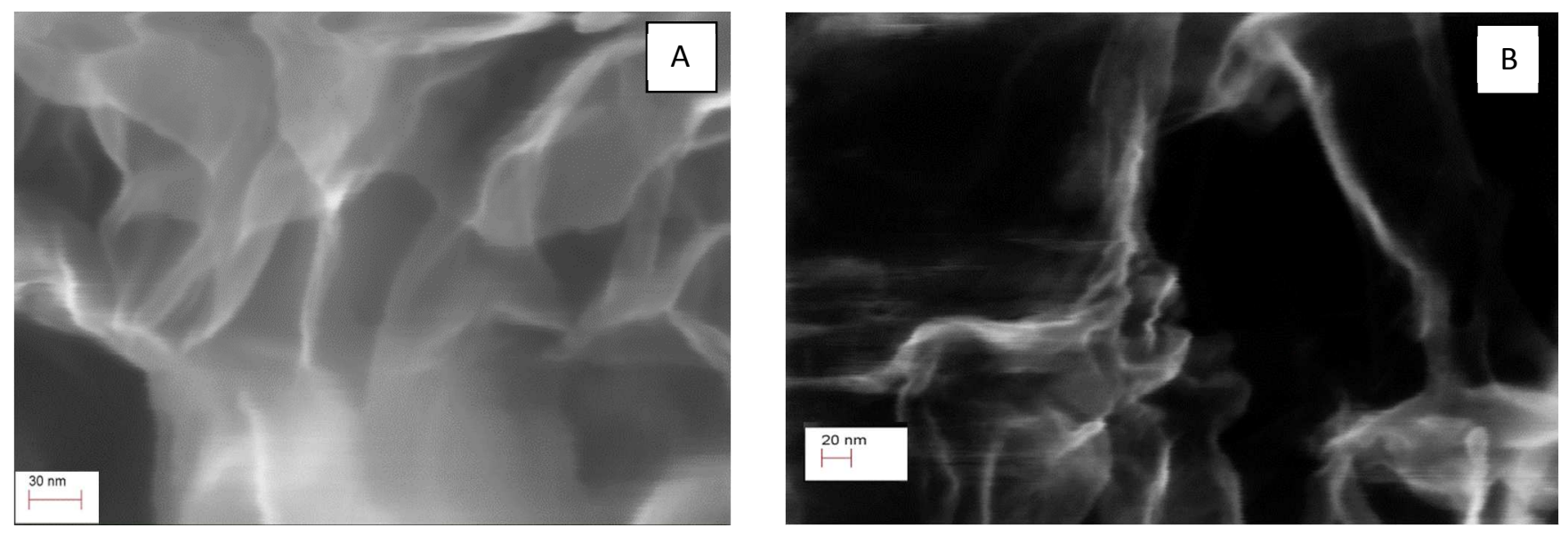

Figure S7: (A) SEM of a discharged dry cathode, (B) SEM of a discharged wet cathode

\section{Super C65 capillary battery}

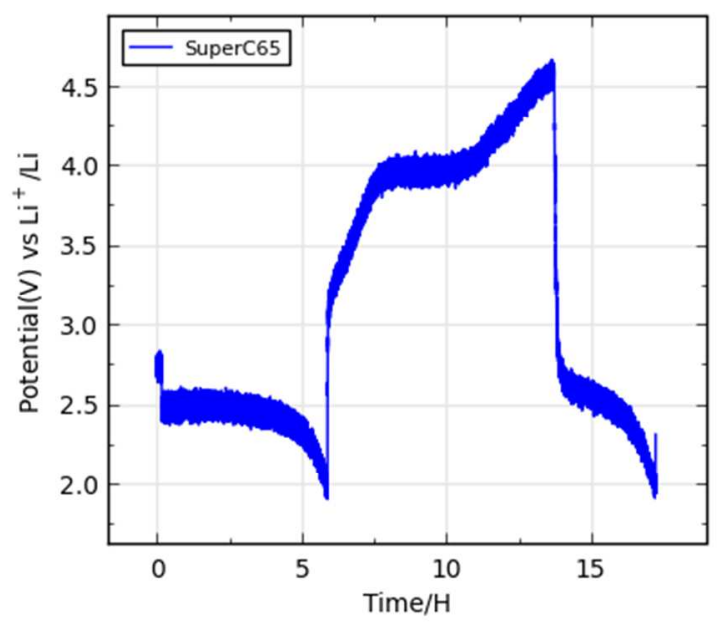

Figure S8: Discharge-charge curve for a Super C65 based capillary battery. 
The Super C65 cathode resulted a battery which showed both discharge and charge. It had a smaller discharge capacity than the TrGO cathode, however, it had a charge with a plateau at $4 \mathrm{~V}$ indicating $\mathrm{Li}_{2} \mathrm{O}_{2}$ decomposition. The Super C65 cathodes had a tendency to overcharge, so the first charge is longer than the first discharge, which may be due to electrolyte decomposition, as seen for carbon based cathodes with a DME based electrolyte. ${ }^{1}$ The difference in battery discharge-charge profile between the two different cathode materials could be explained by difference in the crystalized discharge product or difference in the electron carrying abilities of the discharge products. 


\begin{tabular}{|c|c|c|c|c|}
\hline $\begin{array}{l}\text { Angle/ } \\
\text { o in } 2 \theta\end{array}$ & $\begin{array}{l}d \text {-value/ } \\
\AA\end{array}$ & $\begin{array}{l}\text { Net } \\
\text { Intensity }\end{array}$ & $\begin{array}{l}\text { Gross } \\
\text { Intensity }\end{array}$ & Assignment \\
\hline 19.311 & 2.964 & 2930 & 7860 & \\
\hline 20.380 & 2.810 & 2580 & 7480 & $\mathrm{LiOH}(101)$ \\
\hline 20.644 & 2.774 & 2410 & 7290 & $\mathrm{Li}_{2} \mathrm{O}_{2}(100)$ \\
\hline 21.937 & 2.612 & 2350 & 7120 & $\mathrm{Li}_{2} \mathrm{O}_{2}(101)$ \\
\hline 22.386 & 2.561 & 1870 & 6600 & $\mathrm{LiOH}(110)$ \\
\hline 27.785 & 2.070 & 1990 & 5670 & SS \\
\hline 28.381 & 2.028 & 1630 & 5140 & SS \\
\hline 30.500 & 1.890 & 2010 & 4830 & $\mathrm{Li}_{2} \mathrm{O}_{2}(004)$ \\
\hline 31.977 & 1.805 & 2360 & 4610 & $\mathrm{Li}_{2} \mathrm{O}_{2}(103)$ \\
\hline 32.394 & 1.782 & 2480 & 4550 & $\mathrm{LiOH}(112)$ \\
\hline 35.572 & 1.627 & 3490 & 4080 & SS \\
\hline 36.099 & 1.604 & 3540 & 3840 & $\mathrm{Li}_{2} \mathrm{O}_{2}(104)$ \\
\hline 36.294 & 1.596 & 3670 & 3870 & $\mathrm{LiOH}(211)$ \\
\hline
\end{tabular}

Table S1: The diffraction peaks developed upon discharge of the capillary $\mathrm{Li}-\mathrm{O}_{2}$ battery with the TrGO cathode for position 1. 


\section{Charging of the TrGO cathode in a capillary battery}

During the charge of the TrGO capillary batteries a plateau was formed at $4.5 \mathrm{~V}$. In position 1 only a 19 $\%$ reduction of the $101 \mathrm{Li}_{2} \mathrm{O}_{2}$ diffraction peak was observed, as was expected based on the small charge capacity compared to the discharge for the TrGO battery. Even less decomposition was observed for position $2(6 \%)$. See Figure S9 for a comparison between the first and the last diffractogram during discharge.

For position 1 the diffraction peaks at $19,22.4$ and $32^{\circ}$ in $2 \theta$ was unchanged or decreases slightly upon charge. The diffraction peaks at $20.3,20.6,22$ and $32.5^{\circ}$ in $2 \theta$ decreases in intensity with charge. For position 2 the only observed change in the diffraction peaks upon charge were for the diffraction peaks at $20.4,20.6$ and $22^{\circ}$ in $2 \theta$. However, as the diffraction peaks of position two are of less intensity they are less conclusive. The decrease of the diffraction peaks at 20.6 and $22^{\circ}$ is caused by the small decomposition of $\mathrm{Li}_{2} \mathrm{O}_{2}$ observed both for position 1 and 2, however it is clear that large amount of $\mathrm{Li}_{2} \mathrm{O}_{2}$ was unreduced after charge. The $\mathrm{LiOH}$ diffraction peaks were also observed to diminish upon charge, but plenty of $\mathrm{LiOH}$ intensity was still present at the end of discharge (approx. 80\% intensity left). 

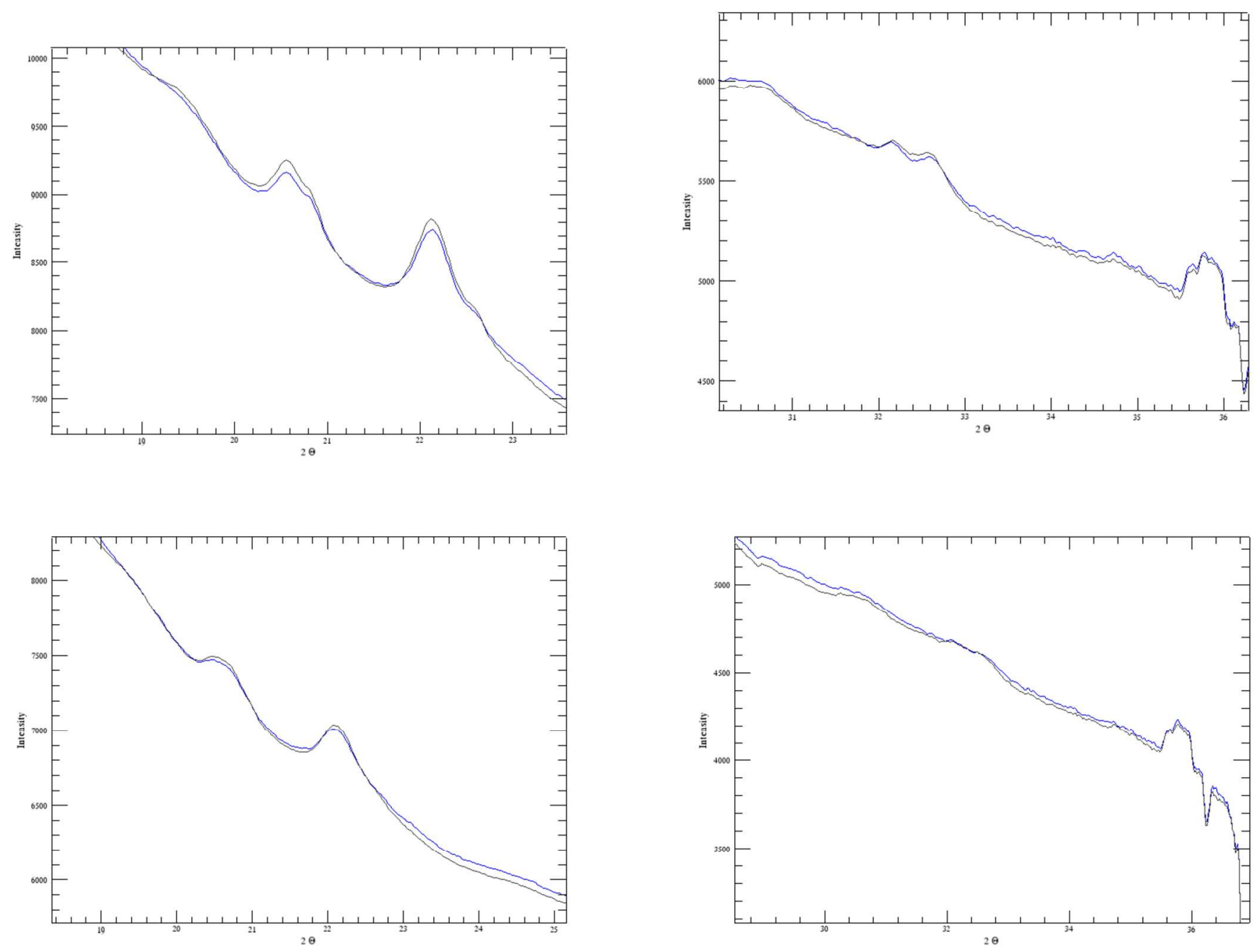

Figure S9: The $1^{\text {st }}$ (gray) and last (blue) X-ray diffractograms from the charge of the TrGO capillary battery. Top: Position 1, Bottom: Position 2. 


\section{Difference between Swagelok cells and the capillary battery}

The different form of LiOH for the different battery types may be caused by difference in the battery set-up. Different types of binders are used in the batteries, but despite possible decomposition of the binder $^{2}$ we do not expect major changes in the chemistry of the composition of the discharge product. The separation of anode and cathode, either by electrolyte or by separator, and the rate of the batteries is another difference between the battery types. We have to remember that the in situ capillary battery was exposed to X-ray radiation which may affect the battery by X-ray accelerated decomposition of $\mathrm{Li}_{2} \mathrm{O}_{2}$ and radiation damage. All these factors could influence the batteries to form different forms of discharge products. Furthermore it was not possible to leak test the capillary batteries and small leaks may be present

\section{References}

(1) McCloskey, B. D.; Bethune, D. S.; Shelby, R. M.; Girishkumar, G.; Luntz, A. C. Solvents ' Critical Role in Nonaqueous Lithium-Oxygen Battery. J. Phys. Chem. Lett. 2011, 2, 1161-1166.

(2) Younesi, S. R.; Hahlin, M.; Bjo, F.; Johansson, P.; Edström, K. Li-O2 Battery Degradation by Lithium Peroxide: A Model Study. Chem. Mater. 2013, 25, 77-84. 